\title{
Management of acute childhood asthma: a prospective multicentre study
}

\author{
T.N. Hilliard*, H. Witten**, I.A. Male*, S. Langton Hewer*, P.C. Seddon*
}

Management of acute childhood asthma: a prospective multicentre study. T.N. Hilliard, $H$. Witten, I.A. Male, S. Langton Hewer, P.C. Seddon. (C)ERS Journals Ltd 2000.

ABSTRACT: Children with acute asthma account for a significant proportion of paediatric hospital admissions, and clear guidelines exist for their care. The aim of this study was to determine their management in the UK.

Over 1 year (February 1995 to January 1996), children aged 1-14 yrs admitted with acute asthma were studied in both teaching and district general hospitals. An admission pro forma was used to collect data prospectively, with a computer-based information management system for the input of admissions in each centre.

Ten centres collected data prospectively, with 1,578 admissions involving 1,352 children (median age $3.6 \mathrm{yrs}$ ). Sixty two per cent of children were $<5$ yrs of age. Sixty three per cent of admissions had initial arterial oxygen saturation $\left(\mathrm{Sa}_{\mathrm{a}}, \mathrm{O}_{2}\right)$ recorded, and, in those older than $5 \mathrm{yrs}, 36 \%$ had their initial peak expiratory flow rate recorded. Systemic steroids were given to $78 \%$. An initial $\mathrm{S}_{\mathrm{a}, \mathrm{O}_{2}}$ of $<\mathbf{9 2 \%}$ was associated with a longer stay in hospital, and also with intravenous treatment. Preventative treatment increased from $42 \%$ on admission to $53 \%$ on discharge. The rates of documented education were low.

This is the largest UK study following publication of national guidelines and shows that there is still room for improvement in the management of children admitted with acute asthma.

Eur Respir J 2000; 15: 1102-1105.
*Royal Alexandra Hospital for Sick Children, and **Terranova Pacific Services (UK) Ltd., Brighton, UK.

Correspondence: T.N. Hilliard, Research Unit, Royal Alexandra Hospital for Sick Children, Brighton BN1 3JN UK. Fax: 44 1273736685 .

Keywords: Admission

asthma

children

management

Received: June 151999

Accepted after revision January 312000

T.N. Hilliard, I.A. Male and S. Langton Hewer were funded by the Rockinghorse Appeal. Portable computers were supplied by Allen \& Hanburys Limited.
Hospital admission rates for childhood asthma have increased markedly during the $1970 \mathrm{~s}-1990 \mathrm{~s}$ [1, 2], and in England they account for $22 \%$ of paediatric admissions among 5-14 yr olds [3]. Guidelines have been set for the inpatient management of asthma in children and adults [4-6], and yet there appear to be inadequacies in hospital care $[7,8]$. In addition, the Audit Commission for England and Wales has identified childhood asthma as an area in which hospital management could be improved [9].

Previous studies have tended to be either retrospective in nature $[2,10-12]$ or prospective but with relatively small numbers of patients $[13,14]$. A multicentre study was therefore initiated to compare practices and outcome for admissions for childhood asthma in the UK. A pilot study was conducted in six centres, collecting information retrospectively from case notes, but this encountered major problems in question design and the recording of data [15].

Therefore, this study was designed to collect data prospectively using a standard method throughout, with the aid of admission pro formas and a computer-based information-management system. The objectives were: to identify the characteristics of children admitted to hospital with acute asthma; to document their management and outcome; to examine differences among participating centres; and to identify factors contributing to outcome.

\section{Methods}

Under the auspices of the British Asthma Audit Survey, paediatricians throughout the UK were invited to parti- cipate in the study. The subjects were children aged 1-14 yrs, admitted with acute asthma, defined as acute wheezing and breathlessness without alternative cause.

An admission pro forma was designed to promote accurate prospective data collection regarding admission, background information and inpatient stay. This was used for the recording of the initial details of the admission, and was integrated into the patient's case notes. Information relating to events following admission was entered stepby-step onto this pro forma. The medical and nursing teams involved in the care of the patients were responsible for the entry of data onto the pro formas.

A computerized database program was specifically designed for the direct input of admission episodes (Asthma Information Management System (AIMS), Terranova Pacific Services Ltd.). A single individual in each centre entered data direct from the pro forma after the admission. Centres were supplied with portable computers and the software for the database. Each centre then sent its data to the co-ordinating centre for analysis. Each child entered into the study was given a unique admission number, which allowed identification of repeat admissions in the analysis. The study ran from February 1995-January 1996.

Data were collected in the following categories: 1) demographic details: age, sex, past medical history, parental smoking, chronic asthma symptoms, and treatment; 2) pattern of asthma and treatment prior to acute episode; 3 ) admission details, including documentation of initial parameters of severity; 4) treatment during admission; 5) outcome; 6) education given and discharge medication; and 7) follow-up arrangements. 
The times of admission and discharge were recorded to the nearest minute.

A scoring system was constructed for the pattern of asthma in the previous 6 months. Scores for night-time cough and wheeze on waking were: 1 for 1 event. week ${ }^{-1}, 2$ for $1-2$ event.week ${ }^{-1}$, and 3 for $\geq 3$ event $\cdot$ week $^{-1}$. Scores for activity-induced symptoms were: 1 for "occasional", 2 for "every time", and 3 for "even after bronchodilator". A total symptom score of 1-3 was labelled mild, 4-6 moderate, and 7-9 severe.

Data were analysed using Microsoft Access (Microsoft Corporation, California, USA) and Minitab Release 11 statistics software (Minitab, Inc., State College, PA, USA). Categorical data were examined by means of the Chisquared test and nonparametric data the Mann-Whitney Utest.

\section{Results}

Sixteen centres accepted the invitation to take part in the study. Six centres were excluded from further analysis because some of their data had been recorded retrospectively from the patients' notes. The remaining ten centres collected all their data prospectively and were a mixture of teaching and district general hospitals. Six centres collected data for the full 12 months of the study, and four for 9 months.

Admissions $(1,578)$ involving 1,352 children were recorded. The median number of admissions from each centre was 143 (range 27-381).

\section{Patient characteristics and pattern of asthma}

Table 1 shows the patient characteristics on first admission during the study. Sixty-six per cent (895) of the children were male and $62 \%(843)$ aged $<5$ yrs. The median age was 3.6 yrs (range 1.0-14.9 yrs). Thirteen per cent (180) of children were admitted more than once during the study period.

Table 2 shows the pattern of asthma and treatment prior to the first admission. Preventative treatment was being taken by $42 \%$ of children, mainly inhaled corticosteroid, with $3 \%$ receiving sodium cromoglycate and $0.4 \%$ salmeterol. Of the 447 children defined as having moderate or severe chronic symptoms of asthma, $60 \%$ were on preventative treatment.

\section{Admission details and treatment}

General practitioner referrals accounted for $56 \%$ of admissions (range 14-82\% between centres). A visit to Ac-

Table 1. - Patient characteristics on first admission

\begin{tabular}{lc}
\hline & Children n (\%) \\
\hline Subject n & 1352 \\
Family history of atopy & $948(70)$ \\
Personal atopy & $506(37)$ \\
Parental smoking & $547(40)$ \\
Preterm birth* & $60(4)$ \\
Birth weight $<1500 \mathrm{~g}$ & $10(0.7)$ \\
Birth weight $<1000 \mathrm{~g}$ & $7(0.5)$ \\
Past history of bronchiolitis & $196(15)$ \\
\hline
\end{tabular}

*: before 37 weeks of gestation.
Table 2. - Pattern of asthma prior to first admission and treatment

\begin{tabular}{lc}
\hline & Children n (\%) \\
\hline Subject n & 1352 \\
Chronic symptoms of asthma & $327(24)$ \\
None & $578(43)$ \\
Mild & $337(25)$ \\
Moderate & $110(8)$ \\
Severe & $538(40)$ \\
Previous admission with asthma & $562(42)$ \\
On preventative treatment & $248(18)$ \\
Home nebulizer supplier & $88(35)^{*}$ \\
General Practitioner & $48(19)^{*}$ \\
Hospital & $86(35)^{*}$ \\
Parents & $26(11)^{*}$ \\
Other & \\
\hline
\end{tabular}

*: percentages refer to those children with a home nebulizer.

cident and Emergency for acute wheezing in the previous $24 \mathrm{~h}$ had occurred in $1 \%$. The most frequent hour of admission was 12:00-13:00 h (9\%); however, 57\% of admissions occurred between 17:00 and 09.00 h. Admissions were evenly distributed throughout the days of the week. Figure 1 shows the frequency of admission in each month, in those centres with 12 months of data $(1,173$ admissions). Two peaks of admissions occur during the year, the first between March and May, and the second from September to November.

Table 3 details the initial arterial oxygen saturation $\left(\mathrm{S}_{\mathrm{a}} \mathrm{O}_{2}\right)$, peak expiratory flow rate and use of systemic steroids. There was significant variation between centres $(\mathrm{p}<0.001)$. Of the 343 children with an initial $\mathrm{Sa}_{\mathrm{a}} \mathrm{O}_{2}$ of $<92 \%, 9 \%$ subsequently received intravenous treatment (steroid or bronchodilator), whereas of the 646 children with an $\mathrm{Sa}_{\mathrm{a}} \mathrm{O}_{2}$ of $\geq 92 \%$, only $2 \%$ received intravenous treatment $\left(\chi^{2}=24.35, \mathrm{p}<0.001\right)$.

Intravenous aminophylline was given in 3\% of admissions, with intravenous salbutamol in only $0.4 \%$. In the three centres using intravenous salbutamol, only in one was it used more frequently than intravenous aminophylline (3 versus $0.7 \%$ of admissions).

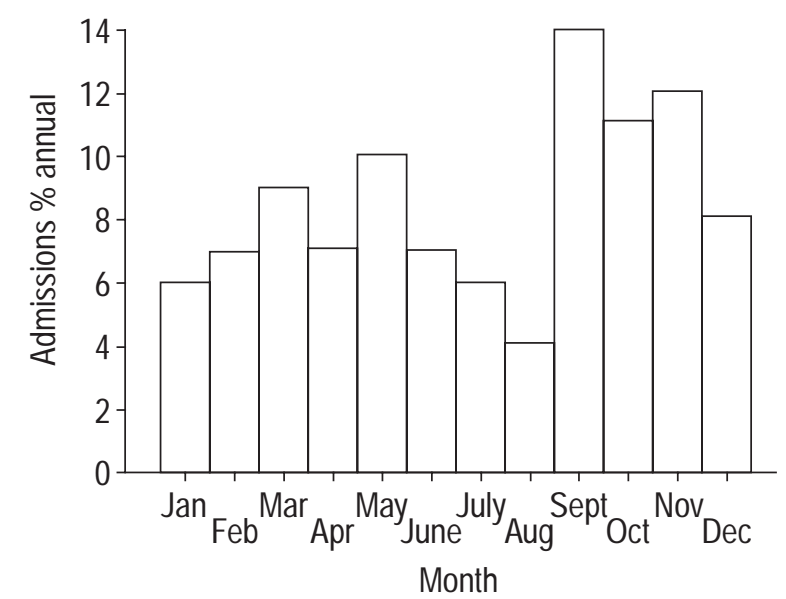

Fig. 1. - Admissions by month in those centres recording data for 12 months ( $\mathrm{n}=1,173)$. Jan: January; Feb: February; Mar: March; Apr: April; Aug: August; Sept: September; Oct: October; Nov: November; Dec: December. 
Table 3. - Initial parameters and use of systemic steroids

\begin{tabular}{lrrc}
\hline & \multicolumn{2}{c}{ Subjects } & \multirow{2}{*}{$\begin{array}{c}\text { Range between } \\
\text { centres \% }\end{array}$} \\
\cline { 2 - 3 } & $\mathrm{n}$ & $\%$ & \\
\hline${\text { Initial } \mathrm{Sa}_{\mathrm{a}, \mathrm{O}_{2}} \text { recorded }}_{\mathrm{Sa}_{\mathrm{a}} \mathrm{O}_{2}<92 \% *}^{989}$ & 63 & $28-100$ \\
$\mathrm{Initial} \mathrm{PEFR} \mathrm{recorded}^{+}$ & 343 & 35 & $20-62$ \\
$\begin{array}{l}\text { Systemic steroids given } \\
\text { during admission }\end{array}$ & 207 & 36 & $14-66$ \\
& 1232 & 78 & $5-94$ \\
\hline
\end{tabular}

Data were based on 1,578 admissions. $*$ : of those recorded; ${ }^{+}$: of those $>5$ yrs (568 admissions). PEFR: peak expiratory flow rate.

\section{Outcome}

The median duration of admission was $28 \mathrm{~h}$ (range 1$784 \mathrm{~h}$ ), with $37 \%$ of admissions lasting $<24 \mathrm{~h}, 53 \%$ 24-72 $\mathrm{h}$, and $10 \%>72 \mathrm{~h}$. Five per cent of admissions were for $<8$ $\mathrm{h}$, and $1.6 \%$ were for $<4 \mathrm{~h}$. There was significant variation between centres regarding duration of admission (range 8$68 \%$ for $<24 \mathrm{~h}, 27-89 \%$ for $24-72 \mathrm{~h}, 3-30 \%$ for $>72 \mathrm{~h}$; all $\mathrm{p}<0.001)$. Of the 11 children admitted to an intensive care unit, one child underwent a period of mechanical ventilation. There were no deaths.

The duration of admission in children with an initial $\mathrm{Sa}, \mathrm{O}_{2}$ of $<92 \%$ was longer than that in those with an initial $\mathrm{Sa}_{\mathrm{a}, \mathrm{O}_{2}}$ of $\geq 92 \%$, (median $36 \mathrm{~h}$ (range $1-288$ ) versus $26 \mathrm{~h}$ (1-784), $\mathrm{p}<0.001,95 \%$ confidence interval (CI) 2.0-8.0). The duration of admission did not differ significantly between those who received systemic steroids and those who did not (median $29 \mathrm{~h}$ versus $24 \mathrm{~h}, \mathrm{p}=0.060,95 \% \mathrm{CI}$ $0.0-5.0)$.

Within 2 weeks of discharge, $1.6 \%$ (25) of children were readmitted. The use of systemic steroids during admission was not associated with readmission within 2 weeks $\left(\chi^{2}=\right.$ $1.61, \mathrm{p}=0.20)$.

\section{Discharge medication, education and follow-up}

Education and changes in preventative treatment during admission are shown in table 4 . There was significant variation between centres in all of these areas (all $\mathrm{p}<0.001)$. Intended follow-up was recorded in $66 \%$ of admissions. This was with the general practitioner in $28 \%$ of cases, a consultant-led clinic in 34\% and a nurse-led clinic in $4 \%$.

Table 4. - Preventative treatment and education

\begin{tabular}{lccc}
\hline & \multicolumn{2}{c}{ Subjects } & $\begin{array}{c}\text { Range between } \\
\text { centres \% }\end{array}$ \\
\cline { 2 - 3 } & $\mathrm{n}$ & $\%$ & \\
\hline $\begin{array}{c}\text { Preventative treatment on } \\
\text { admission (on first admission) }\end{array}$ & 562 & 42 & $28-51$ \\
$\begin{array}{l}\text { Preventative treatment on } \\
\text { discharge (on first admission) }\end{array}$ & 713 & 53 & $32-75$ \\
$\begin{array}{l}\text { Inhaler technique assessed } \\
\begin{array}{l}\text { Self-management plan } \\
\text { given }\end{array}\end{array}$ & 467 & 30 & $0-74$ \\
$\begin{array}{l}\text { Inpatient education } \\
\text { Literature given }\end{array}$ & 459 & 23 & $0-66$ \\
\hline & 241 & 15 & $0-71$ \\
\hline
\end{tabular}

Data on first admission were based on 1,352 admissions; the remaining data were based on all admissions $(1,578)$.

\section{Discussion}

This is the largest UK study of hospital admissions for childhood asthma. The prospective nature of the data collection using an admission pro forma means that the information recorded is more likely to represent what actually occurred with patients than is retrospective data collection. The results show that despite national guidelines there are major deficiencies in several aspects of asthma management with significant variation between hospitals.

One-third of children in the study had had symptoms termed as moderate-to-severe in the preceding 6 months. However only $60 \%$ of these children were on preventative treatment. This suggests that there is still undertreatment despite current guidelines emphasizing the need for regular preventative medication for those with more than mild symptoms [16]. Eighteen per cent of children had a home nebulizer, many of them bought by their parents $(35 \%)$. This is a surprisingly high proportion, given that current guidelines now discourage widespread home use of nebulizers [16].

$\mathrm{Sa}_{\mathrm{a}} \mathrm{O}_{2}$ has been reported previously to be a good predictor of outcome, in terms of requirement for admission and intravenous treatment [17]. However, only $63 \%$ of admissions in this study had their initial $\mathrm{Sa}_{2} \mathrm{O}_{2}$ recorded, despite pulse oximetry being widely available in all of the participating hospitals. In the present study, an initial $\mathrm{Sa}_{\mathrm{a}} \mathrm{O}_{2}$ of $<92 \%$ is not only associated with subsequent intravenous treatment but also significantly associated with increased duration of admission. This emphasizes its importance in the initial assessment of acute asthma. The authors accept that documentation of initial $\mathrm{Sa}_{2} \mathrm{O}_{2}$ may be partly dependent on its value, with a low $\mathrm{Sa}_{2} \mathrm{O}_{2}$ being potentially more likely to be recorded. Only $36 \%$ of children of $>5$ yrs of age had their initial peak flow recorded; this is an age at which many are able to cooperate with this manoeuvre. Peak flow is another important parameter of severity in acute asthma and could be used more often in guiding management in young children [18]. There are other important parameters that are useful in the grading of severity of acute asthma, such as respiratory frequency, cardiac frequency and the presence of wheeze. These were included in the pro forma but were not subjected to analysis for the purposes of this study.

Systemic steroids were given in $78 \%$ of admissions, which is a marked increase from $46 \%$ found in admissions aged 5-14 yrs in 1985 [11]. There was wide variation between centres in the use of systemic steroids, with one centre giving them in as few as 5\% of admissions, and the next lowest giving them in $52 \%$. This first percentage is so low that poor documentation may partly explain this. If the 110 admissions from this centre are excluded from the analysis, the use of systemic steroids is $84 \%$. However, this means that one child in six is not receiving systemic steroids in acute asthma, contrary to current guidelines [16]. There was an increase in those prescribed preventative treatment from $42 \%$ on admission to $53 \%$ at discharge, but this is probably still an inadequate proportion, given that all children in the study had suffered an attack severe enough to require hospital admission. More encouraging however is that only $1 \%$ of children had been seen in an Accident and Emergency department in the $24 \mathrm{~h}$ prior to admission, and only $1.6 \%$ of children were readmitted within 2 weeks of discharge. 
Education and discharge planning are extremely important in the management of childhood asthma. Improving children's and parents' awareness and understanding of asthma, contributes to a positive outcome $[19,20]$. The proportion documented as receiving education in this study was low, as has been found in other recent studies [21]. This is in each of the areas of: inhaler device assessment, education about asthma, self-management plans, and distribution of literature. The short duration of the admissions, with more than one-third staying $<24 \mathrm{~h}$, may have contributed to this. In order to overcome this, a structured discharge package should be considered for all children with acute asthma [20].

There is clearly a difference between omission to perform a particular task and failure to document it. Unfortunately, in this study, it is not possible to distinguish between the two. The authors, therefore, accept that this may lead to an underestimation of actual practice. This may particularly be the case in the area of education and discharge planning. However, documentation is in itself an important part of the management of an admission, and especially when it refers to information given to the family. The authors, therefore, feel that failure of documentation itself is a deficiency in management. The use of a pro forma in this study facilitated documentation without replication of data, maximizing the accurate representation of each admission. The authors would recommend the adoption of pro formas, along with appropriate training of staff with emphasis on careful recording of care during an admission.

This study gives a detailed picture of the management of children admitted with acute asthma in centres throughout the UK. This falls short of current guidelines in terms of treatment, education and recording of important initial parameters. There is therefore still room for improvement.

\footnotetext{
Acknowledgements. The authors would like to thank all those involved in collecting and entering data in the individual centres, D. Robinson for help with the statistical analysis, and T. Newson for helpful comments on the manuscript.
}

\section{References}

1. Strachan DP, Anderson HR. Trends in hospital admission rates for asthma in children. BMJ 1992; 304: 819-820.

2. Anderson HR. Increase in hospital admissions for childhood asthma: trends in referral, severity, and readmissions from 1970 to 1985 in a health region of the United Kingdom. Thorax 1989; 44: 614-619.

3. Department of Health. Hospital Episode Statistics, England: 1994-95. London: Department of Health, 1996.

4. Anonymous. Guidelines on the management of asthma. Statement by the British Thoracic Society, the British Paediatric Association, the Research Unit of the Royal College of Physicians of London, the King's Fund Centre, the National Asthma Campaign, the Royal College of General Practitioners, the General Practitioners in asthma
Group, the British Association of Accident and Emergency Medicine, and the British Paediatric Respiratory Group. Thorax 1993; 48 (Suppl. 2): S1-S24 (errata in Thorax 1994; 49: 96 and 386).

5. Warner JO, Gotz M, Landau LI, et al. Management of asthma: a consensus statement. Arch Dis Child 1989; 64: 1065-1079.

6. International Paediatric Asthma Consensus Group. Asthma, a follow-up statement. Arch Dis Child 1992; 67: 240248.

7. Pearson MG, Ryland I, Harrison BDW. Comparison of the process of care of acute severe asthma in adults admitted to hospital before and 1 year after the publication of national guidelines. Respir Med 1996; 90: 539-545.

8. Harrison BDW, Pearson MG. Audit in acute severe asthma - who benefits? JR Coll Physicians Lond 1993; 27: 387-390.

9. The Audit Commission for England and Wales. Children First: a Study of Hospital Services. London, Her Majesty's Stationery Office (HMSO), 1993.

10. To T, Dick P, Feldman W, Hernandez R. A cohort study on childhood asthma admissions and readmissions. Pediatrics 1996; 98: 191-195.

11. Anderson HR. Trends and district variations in the hospital care of childhood asthma: results of a regional study 1970-85. Thorax 1990; 45: 431-437.

12. Anderson HR, Bailey P, West S. Trends in the hospital care of acute childhood asthma 1970-8 a regional study. BMJ 1980; 281: 1191-1194.

13. Bucknall CE, Robertson C, Moran F, Stevenson RD. Management of asthma in hospital: a prospective audit. BMJ 1988; 296: 1637-1639.

14. Conway SP, Littlewood JM. Admission to hospital with asthma. Arch Dis Child 1985; 60: 636-639.

15. Langton Hewer S, Hambleton G, McKenzie S, et al. Asthma audit: a multicentre pilot study. Arch Dis Child 1994; 71: 167-169.

16. Anonymous. Asthma in adults and schoolchildren. The General Practitioner in Asthma Group, British Association of Accident and Emergency Medicine, the British Paediatric Respiratory Society and the Royal College of Paediatrics and Child Health. Thorax 1997; 52 (Suppl. 1): S1-S24.

17. Geelhoed GC, Landau LI, Le Souef PN. Evaluation of $\mathrm{Sa}, \mathrm{O}_{2}$ as a predictor of outcome in 280 children presenting with acute asthma. Ann Emerg Med 1994; 23: 12361241.

18. Taylor MR. Asthma: audit of peak flow rate guidelines for admission and discharge. Arch Dis Child 1994; 70: 432434.

19. Madge P, McColl J, Paton J. Impact of a nurse-led home management training programme in children admitted to hospital with acute asthma: a randomised controlled study. Thorax 1997; 52: 223-228.

20. Wesseldine LJ, McCarthy P, Silverman M. Structured discharge procedure for children admitted to hospital with acute asthma: a randomised controlled trial of nursing practice. Arch Dis Child 1999; 80: 110-114.

21. Ordonez GA, Phekan PD, Olinsky A, Robertson CF. Preventable factors in hospital admissions for asthma. Arch Dis Child 1998; 78: 143-147. 